
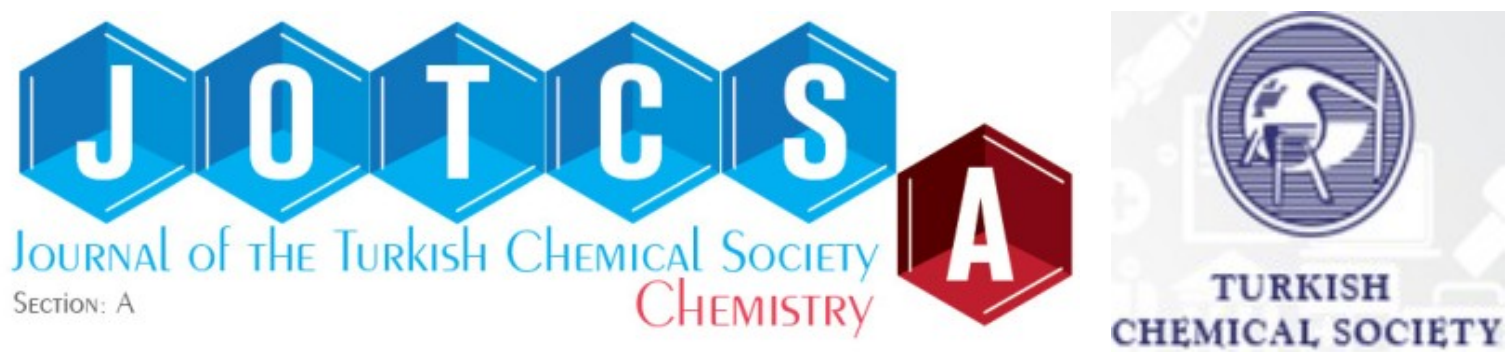

\title{
The Investigation of the Effect of Mineral Oils which Have Different Specifications on The Performance of Palm- and Tallow-Based Soap Recipes
}

\author{
Esra Gül* $\triangle$ iD, Aslı Özge Avcı Tuna $\triangle(D$, Özlem Esen $\triangle$ iD \\ Evyap Sabun, Yağ ve Gliserin San. Tic. A.Ş., 34957, Istanbul, Turkey.
}

\begin{abstract}
In this work, three different types of mineral oils, with the same amount (1\% as a ratio), have been added to two different soap recipes from animal origin oils and vegetable-derived fatty acids that have the same rate of foaming agent and similar critical specification values. The $\mathrm{pH} /$ conductivity, foaming performance, hardness, and pellet tests were applied to the soaps obtained; and the results were analyzed by comparing the effects of different specifications of mineral oil. The result of this study, the effect of the addition of mineral oils on the soap samples were clarified and characterized by advanced research.
\end{abstract}

Keywords: Soap, mineral oils, pH, conductivity, foam performance.

Submitted: May 27, 2019. Accepted: January 15, 2020.

Cite this: Gül E, Avcı Tuna A, Esen Ö. The Investigation of the Effect of Mineral Oils which Have Different Specifications on The Performance of Palm and Tallow Based Soap Recipes. JOTCSA. 2020; 7(1): $287-94$.

DOI: https://doi.org/10.18596/jotcsa.570449.

*Corresponding author. E-mail: esgul@evyap.com.tr.

\section{INTRODUCTION}

Soap is a product obtained from the chemical reactions of directly vegetable and animal oils or the chemical reactions of fatty acids obtained from these oils with alkaline hydroxides $(1,2)$. The saponification processes used in soap formulas in the industry for many years are based on a simple neutralization system. In this type of process, saponification occurs by mixing the vegetable and animal oils with the appropriate amount of alkaline substances and exposing them to appropriate heat. The natural saponification reactions are given below (2-4).

\section{$(\mathrm{RCOO}){ }_{3} \mathrm{C}_{3} \mathrm{H}_{5}+3 \mathrm{NaOH}$ vegetable and animal oils}

Since soaps are both the alkaline metal salts of fatty acids and the surfactant material, they are used as cleaning agents. Natural fats and oils hydrolyzed as fatty acids are aliphatic monocarboxylic acids (5). Oleic, stearic, palmitic, myristic, and lauric acids are mostly used as fatty acids (6). The basic process of soap making has not changed since 2000 years. In this method, the solid oils or liquid oils are saponified with an alkali, and then the soap is removed by adding salt to the mixture. Major changes in production; pretreatment of solid oils or liquid oils and making the prepared soap usable. Industrial processes such as hydrolysis, solvent extraction of oils, 
hydrogenation, liquid-liquid extraction have led to the preparation of better-quality raw materials. Besides, batch manufacturing has been replaced by continuous processes (7-14). Fatty acid saponification mechanisms were given in two reactions below $(2,3)$.

Hydrolysis part;

$$
\begin{aligned}
& (\mathrm{RCOO})_{3} \mathrm{C}_{3} \mathrm{H}_{5}+3 \mathrm{H}_{2} \mathrm{O} \longrightarrow 3 \mathrm{RCOOH}+\mathrm{C}_{3} \mathrm{H}_{5}(\mathrm{OH})_{3} \\
& \begin{array}{lll}
\text { vegetable and } & \text { fatty } & \text { acid } \\
\text { animal oils } & \text { water } &
\end{array}
\end{aligned}
$$

Saponification part;

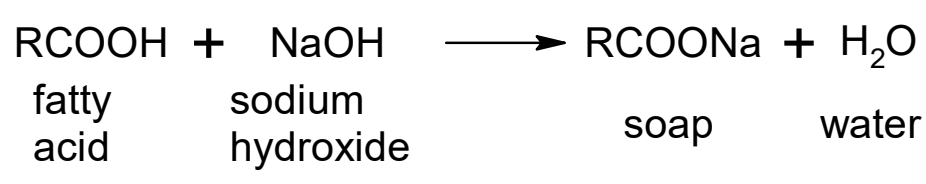

\begin{tabular}{|c|c|c|c|c|}
\hline & Trade Name & INCI Name & $\begin{array}{c}\text { Viscosity } \\
\text { (cPs) }\end{array}$ & $\begin{array}{l}\text { Density } \\
\left(\mathrm{g} / \mathrm{cm}^{3}\right) \\
\end{array}$ \\
\hline Mineral Oil 1 & Mineral Oil Light & $\begin{array}{l}\text { white mineral oil } \\
\text { (petroleum) }\end{array}$ & 11.20 & 0.82 \\
\hline Mineral Oil 2 & Mineral Oil Medium & $\begin{array}{l}\text { white mineral oil } \\
\text { (petroleum) }\end{array}$ & 45.60 & 0.85 \\
\hline Mineral Oil 3 & Mineral Oil Heavy & $\begin{array}{l}\text { white mineral oil } \\
\text { (petroleum) }\end{array}$ & 132.00 & 0.87 \\
\hline
\end{tabular}

Table 1. Viscosity and density values of various mineral oils.

\begin{tabular}{|c|c|c|}
\hline SOAP BASE & $\begin{array}{c}\text { Vegetable Oil Acids } \\
901078 \text { TFM }\end{array}$ & $\begin{array}{c}\text { Animal Oil } \\
901078 \text { TFM }\end{array}$ \\
\hline Total Fatty Acid Matter, \% Min & $78.00 \mathrm{~min}$. & $78.50 \mathrm{~min}$ \\
\hline Free Fatty Acid (as Oleic), \% & 1.50 max. & 1.50 max. \\
\hline Free Alkali (as $\mathrm{NaOH}$ ), \% & Absent & absent \\
\hline Chlorides (as $\mathrm{NaCl}$ ), \% & $0.45-1.05$ & 1.00 max. \\
\hline Glycerin, \% & 1.00 max. & 1.00 max. \\
\hline Unsaponifiable Matter,\% & 1.00 max. & 1.00 max. \\
\hline Volatile Matter $\left(105^{\circ} \mathrm{C}\right), \%$ & $12.00-14.50$ & 15.00 max. \\
\hline
\end{tabular}

Table 2. Critical spec values of soap formulas.

Mineral oils are clear, colorless, and oily liquids that are by-products of the distillation of petroleum (15). Mineral oils are natural materials obtained from various sources. Oil is a mixture of liquid hydrocarbons and other chemical compounds. These are waxes, paraffin, sulfur derivatives, organic aromatic compounds, solid components, etc. (16). Mineral oil is the major source of our liquid fuels and petrochemicals. It consists of long straight-chain alkanes and is contaminated by compounds containing sulfur, nitrogen, and metals, mostly as heavy heterocyclic aromatics and as metalloporphyrin-type materials. Viscous properties of mineral oils are important for technological processes. Maintenance of characteristics of pavements or other compounded products depends on their viscoelastic properties and mechanical strength; the latter is most likely related to the viscoelasticity of material.

In cosmetics, mineral oil helps reduce water loss from a person's skin, helping keep the skin moisturized. It is also inert, which makes it less likely to cause a skin reaction. According to one recent study, mineral oil is preferable for many different skin types, including a baby's sensitive skin. The purified type of mineral oils, considering cosmetic grade, have been using in products like baby oil and cold creams (17). Mineral oil is an inert, chemically stable ingredient, with a long history of safe use in common topical applications. The Food Additives (FDA) regulations, the 
Cosmetic Ingredient Review (CIR) and the Cosmetics Directive of the European Union allow the use of mineral oil in cosmetics and personal care products with no listed restrictions (17). This study presents mineral oils effect in soap products since there is no research to investigate the effect of mineral oils in this area.

White mineral oil (petroleum) a highly refined petroleum mineral oil consisting of a complex combination of hydrocarbons obtained from the intensive treatment of a petroleum fraction with sulfuric acid and oleum, or by hydrogenation, or by a combination of hydrogenation and acid treatment. Additional washing and treating steps may be included in the processing operation. It consists of saturated hydrocarbons having carbon numbers predominantly in the range of $\mathrm{C} 15$ through C50 (18). In this study, three mineral oils, white mineral oils (petroleum), that have different viscosity value, was used to investigate the effect of viscosity of mineral oils on a soap. Mineral oil 1 , Mineral oil 2 and Mineral oil 3 have different viscosity $11.20,45.60$ and 132 cPs, respectively.

Three different mineral oils (Table 2), with the same amount, have been added to two different soap formulas from animal origin oils and vegetable-derived fatty acids (Table 1 ) that have the same rate of foaming agent and similar critical specification values. The $\mathrm{pH} /$ conductivity, foam performance, hardness and pellet (mush) tests were applied to the eight hand soaps obtained; and the results were analyzed by comparing the effects of different specifications of the mineral oil. The result of this study, the effect of the addition of mineral oils on the eight soap samples were clarified and characterized by advanced research analysis.

\section{MATERIALS AND METHODS}

\section{Materials and Characterization}

All mineral oils were obtained from Sonneborn and used as received. Soaps were obtained from Evyap Sabun Malaysia Sdn. Bhd as two forms; produced with animal origin oils and vegetable-derived fatty acids. Four soap samples were obtained from animal origin oil, in which three of them contain $\% 1$ of three different mineral oils, as one is blank. The same procedure was applied to the soap samples obtained from vegetable-derived fatty acids.

\section{Foaming Test Method:}

$0.4 \mathrm{~g}$ of soap sample was planed and put into a beaker. $1000 \mathrm{~mL}$ of distilled water was added on it and homogenized at $3600 \mathrm{rpm}$ for $5 \mathrm{~min}$. After 5 min, water was discharged into 3 measuring cylinders with $50 \mathrm{~mL}$ capacity. Each of the measuring cylinders was turned in a rotation tool for 30 seconds for finding a foam value. Then the first value of foam is marked. After $15 \mathrm{~min}$ and 30 min, the second value and third value of foam are marked, respectively.

To determine the foaming performance of soaps, the foaming test method was applied to soap samples.

\section{Pellet (Mush) Test Method:}

The soap weight without a fork and with a fork (dry weight) was measured. Mush part of the soap was determined that is marked with a knife as from fork part. The soap was put into the beaker and distilled water was filled up the mark and waited for 2 hours at $25^{\circ} \mathrm{C}$. After 2 hours, the water was drained and waited for $5 \mathrm{~min}$. After 5 min, the weight with mush is measured. Then the mush part is cleaned and again the soap is weighed. The following calculations were applied:

weight with mush $(g)$ - weight without mush $(g)=$ weight of mush $(\mathrm{g})$

Weight of mush without water $(\mathrm{g})=$ dry weight $(\mathrm{g})$ - weight without mush (g)

water uptake $(\mathrm{g})$ = weight with mush (g) - dry weight (g)

\section{Hardness Test:}

Hardness analysis was performed by using the LTCM-100 Chatillian Metek instrument to measure the hardness value of soap samples.

pH and conductivity measurement:

Different concentrations of soap solutions were prepared as $1 \%, 5 \%$ and $10 \%$ in water to determine the $\mathrm{pH}$ and conductivity of soap samples. The $\mathrm{pH}$ values were measured from solutions by using a $780 \mathrm{pH}$ meter Metrohm with a glass electrode. The conductivity measurements were performed on a 905 Titrande Metrohm conductivity meter with a glass electrode at $25^{\circ} \mathrm{C}$.

\section{RESULTS AND DISCUSSION}

Figure 1 shows the conductivity changing graphs. It has been obtained that different concentrations of three different mineral oils, which were added to two different soap forms obtained from fatty acids of vegetable oils and directly from animal oil give different results. 


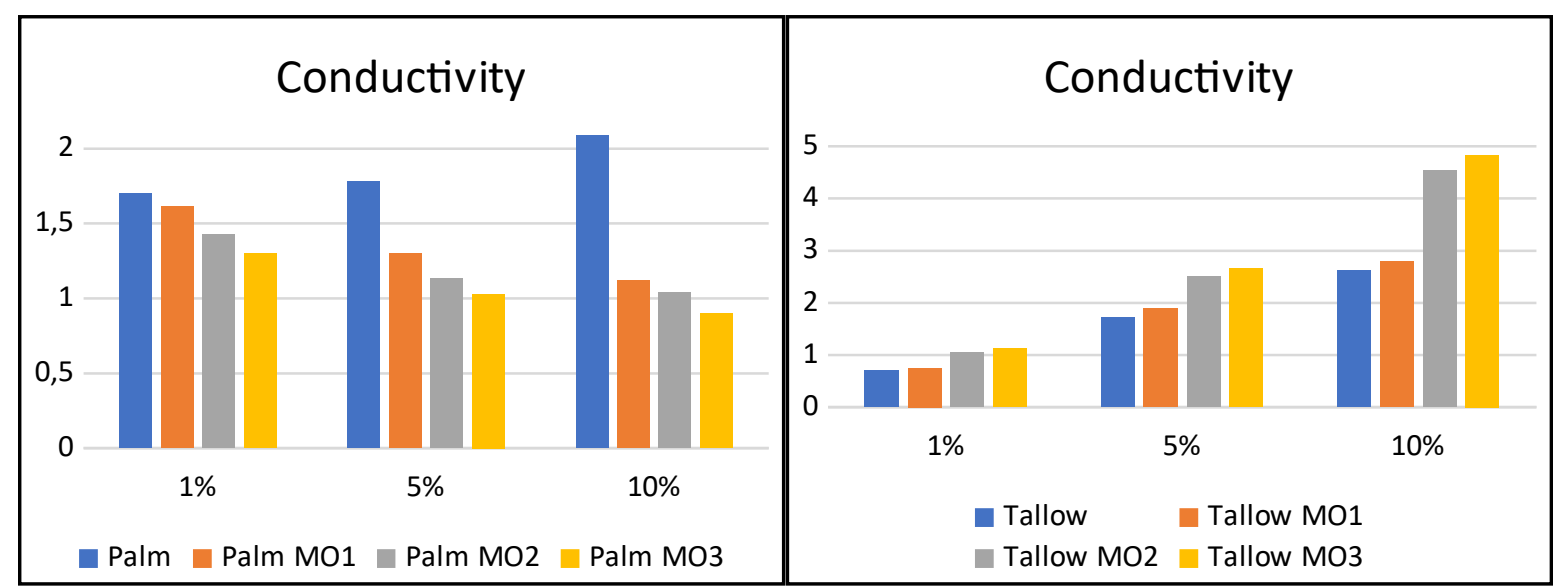

Figure 1. Variation graph on the conductivity of 3 different mineral oils based on palm and tallow at different concentrations.

In this part of the study, the effects of mineral oil on the conductivity of soap were investigated. The electrical conductivity is a magnitude that describes the ability of a material or solution to conduct an electric current. The electrical conductivity of a solution depends on the number and mobility of ions and charged particles present in the solution (19). The soaps obtained from fatty acids of vegetable oils had to decrease of conductivity with the addition of mineral oils. On the other hand, the increase in the conductivity of the soap was measured with the addition of mineral oils in soaps obtained from animal oils. It is thought that this may change depending on the movement of fatty acids and $\mathrm{Na}^{+}$ions in the content of soaps.

Although differences in conductivity measurements were determined, there was no difference in $\mathrm{pH}$ values. This shows that mineral oils do not affect the $\mathrm{pH}$ values of the soap. The graph of $\mathrm{pH}$ and conductivity values are given in Figure 2.

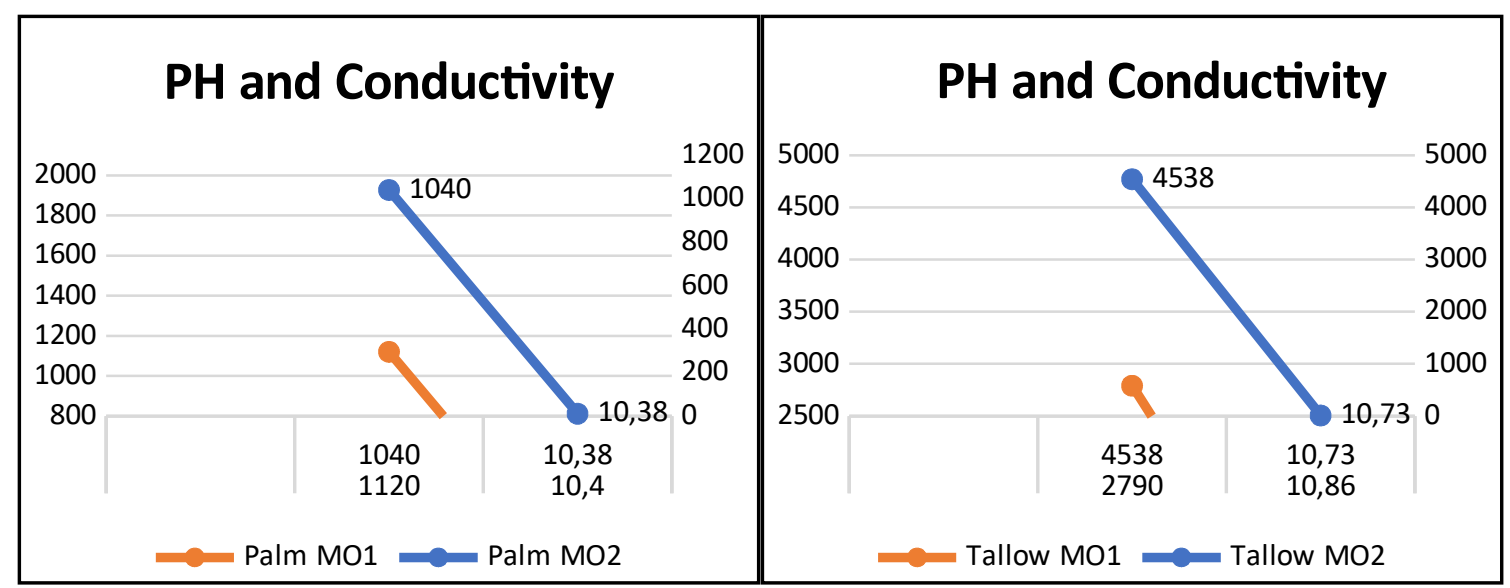

Figure 2. Graphs of change in conductivity and $\mathrm{pH}$ on 3 different mineral oils based on palm and tallow at $25^{\circ} \mathrm{C}$.

In the second part of the study, the foam performance of vegetable oils' fatty acids soaps and animal oils' soaps, were evaluated by "foam volume measurement" after adding different mineral oils with different specifications. The graphs of the measurement results are given in Figure 3 . The $X$-axis shows the foam volume in percent and the $\mathrm{Y}$-axis shows the time axis. 

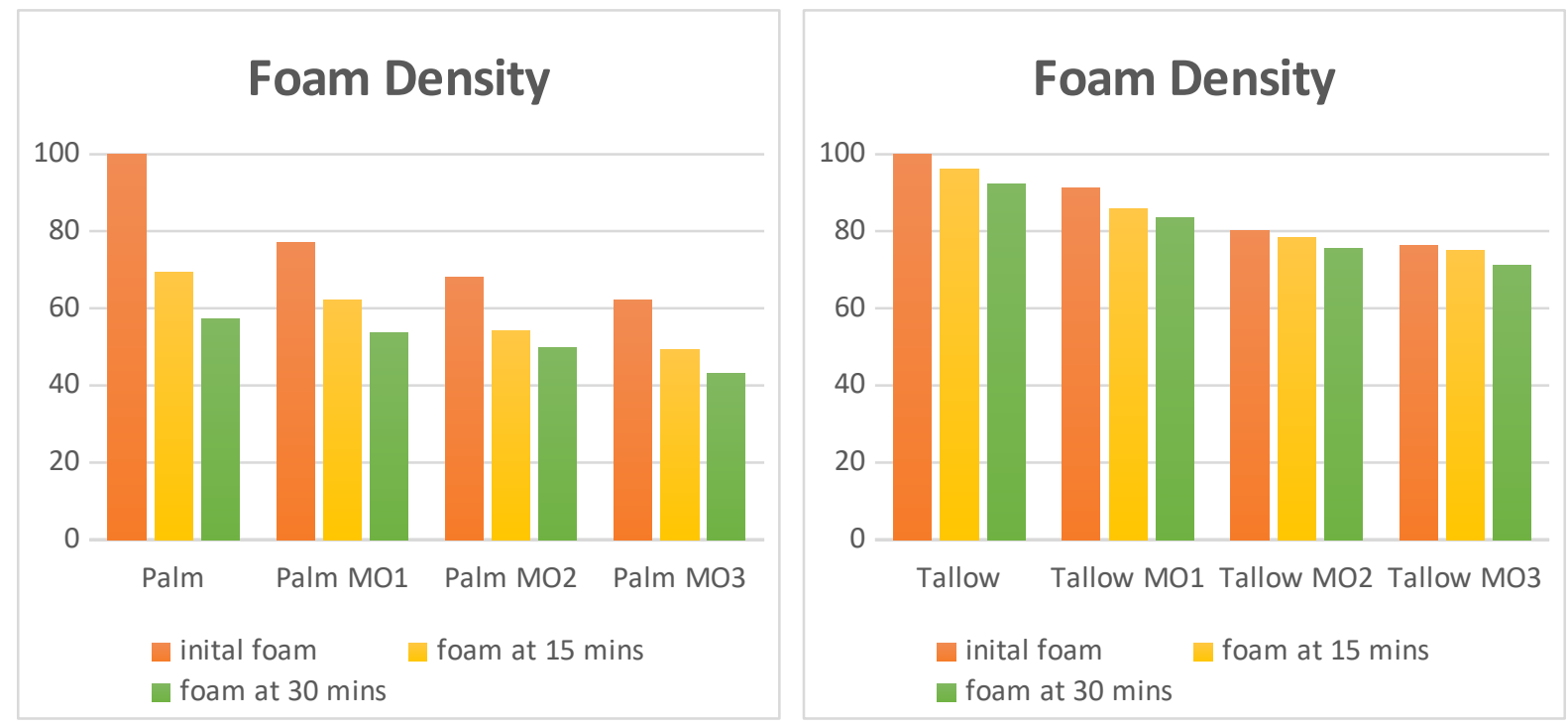

Figure 3. Foam volume values of 3 different mineral oils based on palm and tallow.

The results show that $1 \%$ of mineral oils 1,2 and 3 adding to the vegetable-based soap recipe, the measure of foam volume decreased by $20 \%, 25 \%$, and $40 \%$, respectively.

In animal-derived recipes, when the effect of $1 \%$ of mineral oils adding on the foam was examined, it was observed that it was reduced by a maximum of $24 \%$. As a result of the studies, it was seen that mineral oils have negatively affected the foam performance of soap in both soaps. However, this effect is higher based on Palm.

When mineral oils are compared by themselves, it is observed that primarily mineral oil 3 has the most negative effect than the others on both animal and vegetable-based foam.

With the addition of mineral oil, a reduction in the amount of foam in both soap formulations was observed. It was determined that this decrease is related to the viscosity of mineral oils. The viscosity values of mineral oils are given in Table 2. When the data in Table 2 were taken together with the soap foam performance test of the soap, it was revealed that the mineral oil had a structural effect on the foam. As a result of the study, it was observed that mineral oils caused a decrease in the amount of foam linearly from the low viscosity value to the high viscosity by the addition of soap.

In the third part of the study, hardness values were measured and evaluated after the addition of mineral oils in 3 different specs to 2 formula prescriptions which are in the form of animal oils and vegetable-derived fatty acids at $25^{\circ} \mathrm{C}$.

In animal-based formulas, it was observed that all three types of mineral oils decreased the hardness of soap, while all mineral oils increased the hardness by creating an opposite effect on the palm. The viscosity and density values of mineral oils are given in Table 2 .

The evaluation of hardness changes of plant-based and animal-based formulas, together with \% pellet changes, indicating softening of the soap and residue, were added to the studies and plotted in Figure 4. 


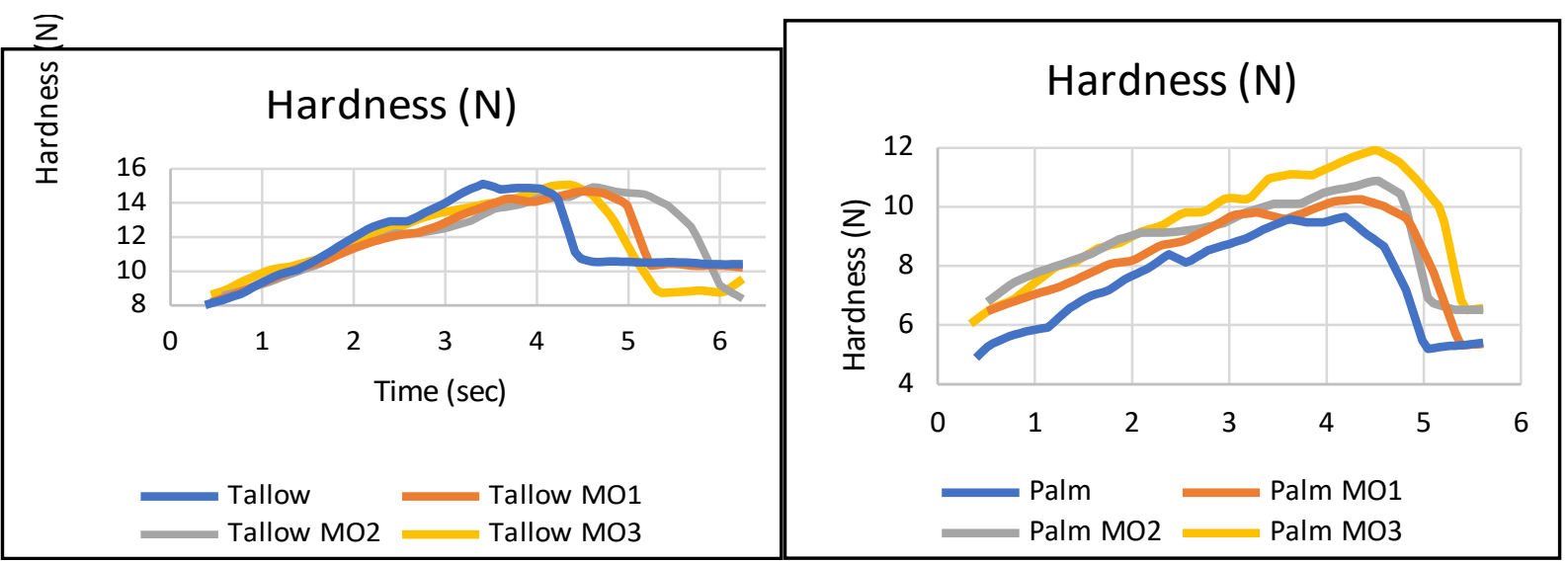

Figure 4. Hardness graphs of soaps produced with 3 different mineral oils on the base of Palm and Tallow at $25^{\circ} \mathrm{C}$

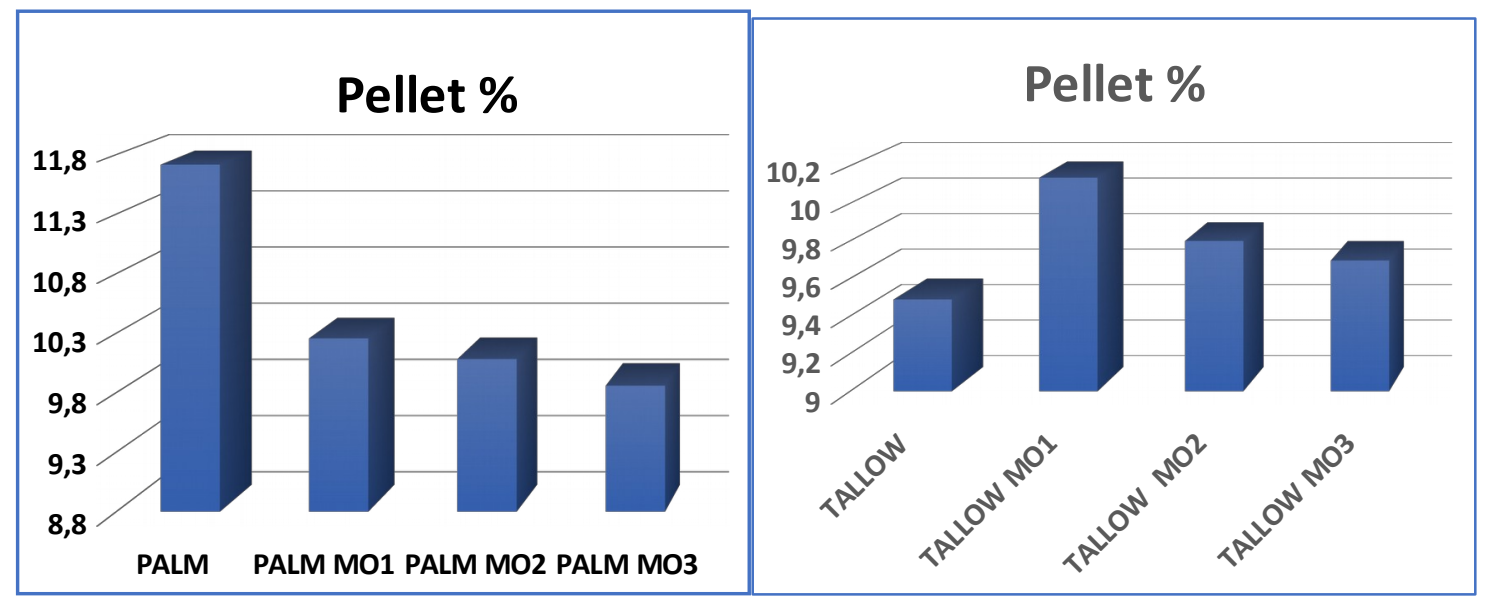

Figure 5. Pellet (\%) change graph of soaps produced with 3 different mineral oil based on Palm and Tallow at $25^{\circ} \mathrm{C}$.

According to the measured results, the addition of mineral oils in plant-based reduced the amount of pellet; the addition of mineral oils in animal origin prescriptions increased the amount of pellet formation.

These results also support the hardness values of soaps of the same formulas. The harder the soap, the less the formation of the soap pellets.

\section{CONCLUSION}

Consequently, this study results showed the following:

- No significant difference was found by the addition of mineral oils at the $\mathrm{pH}$ of all soaps. This shows that the soap base and mineral oil do not affect the $\mathrm{pH}$ value of the soap.

- At the vegetable-derived fatty acid soap formulations, it was observed that the conductivity decreases by the addition of any kind of mineral oils to the soap, while the conductivity of the soap increased with the addition of mineral oils to animal-derived soaps.
- $\quad$ Although there was no difference in $\mathrm{pH}$ values, differences in conductivity measurements were determined. This is thought to be due to the movement of the fatty acids and $\mathrm{Na}^{+}$ions in the content of soaps.

- When the effects of the performance of foaming evaluated with different specs of mineral oils addition to both vegetable-derived fatty acid soaps and animal oils soaps both had a reduction of foaming. In the same study, it was determined that the foam performance of especially vegetable origin recipes were affected more from mineral oils in a negative way compared to animal-based recipes.

- It was measured that, with the addition of mineral oils that cause a decrease in the amount of foam, from viscosity low mineral oil to viscosity high mineral oil in correlation.

- It was measured that mineral oils with different specs make vegetable-derived fatty acid soaps harder but animal oil-based soaps softer.

- As a result of hardness increase the pellet $\%$ of palm soap had a decrease and as a result of softness animal oil-based soaps had an increase at pellet percentage. 
In conclusion, these findings have shown that $\% 1$ of mineral oil 3 adding has decreased foam volume $40 \%$. In the future, Mineral oil 3 can be considered as a defoaming agent for the soap-based detergent industry.

\section{REFERENCES}

1. TSE Sabun Türk Standardı, [cited 2018 Nov 3], Available from: https://intweb.tse.org.tr/standard/standard/Stand ard.aspx?

0811180511151080511041191101040550471051 0212008811104311310407308806612207411209 9075071049107075

2. Spitz L. Soap Manufacturing technology. London, United Kingdom Academic Press and AOCS Press, Second edition; 2018.

3. Schumann K., Siekmann K. Soaps. Ullman's Encylopedia of Industrial Chemistry. 1993, A(249) : 247-266.

4. O'Connor S._Rudkowska I., Chapter Two Dietary Fatty Acids and the Metabolic Syndrome: A Personalized Nutrition Approach. Advances in Food and Nutrition Research. 2019, 87, 43-146.

5. Menaa F., Bouzid Menaa B., Kahn B.A., Menaa A., Chapter 2 - Trans Fats and Risks of Cardiovascular Diseases: Facts or Artifacts. Handbook of Lipids in Human Function, 2016, 2138.

6. Sabun ve Deterjan Endüstrileri, Bölüm II, 2019. Available from: http://webcache.googleusercontent.com/search? $\mathrm{q}=$ cache: sqBvxybAONQJ: content.Ims. sabis. sakarya .edu.tr/Uploads/65467/49523/b\%25C3\%25B6I $\% 25 \mathrm{C} 3 \% 25 \mathrm{BCm}-$

$\% 25 \mathrm{C} 4 \% 25 \mathrm{~B} 1 \% 25 \mathrm{C} 4 \% 25 \mathrm{~B} 1$ sabun ve deterjan k

$\% 25 \mathrm{C} 4 \% 25 \mathrm{~B} 1 \mathrm{sa} \cdot \mathrm{doc}+\& \mathrm{~cd}=1 \& \mathrm{hl}=\mathrm{tr} \& \mathrm{ct}=\mathrm{clnk} \& \mathrm{gl}=\mathrm{tr}$

7. Hall N., Implications of Soap Structure for Formulation and User Properties. Soap Manufacturing Technology (Second Edition). 2016,1-33 p.

8. Hill M., Moaddel T., Soap Structure and Phase Behavior. Soap Manufacturing Technology. 2016, 35-54 p.

9. Alpar S.R., Organik Sınai Kimya, İstanbul Üniversitesi Kimya Fakültesi Yayınları, İstanbul, 1969.
10. Alpar S.R., Hakdiyen M.İ., Bigat T. Sınai Kimya Analiz Metodları, İstanbul Üniversitesi Kimya Fakültesi Yayınları, İstanbul, 1971.

11. Bektaşoğlu S.Y. İgeme Ürün Profili. İgeme, 1995, 4, 1-20 p.

12. DPT. Kimya Sanayinin Genel Değerlendirilmesi ve Yatırım Alanları Özel İhtisas Alt Komisyon Raporu, Devlet Planlama Teşkilatı, 1991.

13. Koç, N., Köpük ve Köpürme prensipleri, Available from: http://www.kmo.org.tr/resimler/ekler/de0e671163 cd540 ek.pdf?dergi $=68$

14. Douguet M., Picard C., Savary G., Merlaud F., Loubat-Bouleuc F., Grisel M. Spreading properties of cosmetic emollients: Use of synthetic skinsurface to elucidate structural effect. Colloids and Surfaces B: Biointerfaces , 2017, 154, 307$314 \mathrm{p}$.

15. The Editors of Encyclopaedia Britannica, Mineral oil [Internet]. Encyclopædia Britannica Encyclopædia Britannica inc., 2019 [cited 2019 Nov 27]. Available from: https://www.britannica.com/technology/mineral-oil

16. Prof. Dr.Alexander Ya. Malkin, Prof. Dr.Avraam I Isayev, Applications of Rheology, Rheology Concepts, Methods, and Applications (Second Edition), 2012. Chapter 6, 365-420 p. Available from: https://doi.org/10.1016/B978-1895198-49-2.50011-6

17. Mineral oil [Internet]. 2020 ChemicalSafetyFacts.org. [cited 2019 Nov 27]. Available from: https://www.chemicalsafetyfacts.org/mineral-oil/

18. Cosmetics - CosIng, Ingredient: PARAFFINUM LIQUIDUM [Internet], European Commission, Internal Market, Industry, Entrepreneurship and SMEs, Sectors, Cosmetics, CosIng, [cited 2019 Nov 27]. Available from: https://ec.europa.eu/growth/tools-databases/cosin $\mathrm{g} /$ index.cfm?

fuseaction $=$ search. details $v 2 \& i d=35850$

19. Taherian R., The Theory of Electrical Conductivity. Electrical Conductivity in PolymerBased Composites. Experiments, Modelling, and Applications, Plastics Design Library. 2019, 1-18 p. 
Gül E, Avcı Tuna AÖ, Esen Ö. JOTCSA. 2020; 7(1): 287-294.

RESEARCH ARTICLE 